Original Article

\title{
FORMULATION AND DESIGN OF EXTENDED RELEASE MATRIX TABLETS OF ZIDOVUDINE HYDROCHLORIDE: A STUDY ON EFFECT OF VARIOUS GRADES OF ETHOCEL AND HPMC
}

\author{
HAREKRISHNA ROY \\ Department of Pharmaceutics, Nirmala College of Pharmacy, Atmakur (Vill), Mangalagiri (M), Guntur, Andhra Pradesh, India \\ Email: hareroy@gmail.com
}

Received: 13 Feb 2017 Revised and Accepted: 01 Feb 2018

\begin{abstract}
Objective: The current research was an attempt to formulate and design an extend release dosage form of zidovudine hydrochloride using various grades of ethyl cellulose (ethocel) such as ethocel 4CPS, ethocel 7 CPS and aqualon T10 Pharm EC with two grades of hydroxy propyl methyl cellulose (HPMC K4M and HPMC K15M).

Methods: Pilot scale batches of nine formulations were prepared using kollidon and adopting wet granulation technique. Physiochemical properties of tablet and granules were examined prior compression to get tablet. Tablets were characterized as drug content, percentage weight variation, thickness, Hardness, percentage friability and in vitro drug release pattern and studied for 12 hour in USP Type-II apparatus using $900 \mathrm{ml}$ Phosphate buffer at $37 \pm 0.5^{\circ} \mathrm{C}$. The dissolution release profile of drug in tablet was performed by various drug release kinetic modelling.

Results: The result revealed formulation F8 containing ethocel 7CPS and aqualon T10 was able to delay the pure drug release for $12 \mathrm{~h}$ and followed Higuchi pattern. Whereas; formulations containing only ethocel 4CPS provided earlier drug release. Dissolution data of promising formulation were analysed with innovator formulation for similarity factor (f2), exhibited an acceptable value more than 50. FT-IR (fourier-transform infrared spectroscopy) and DSC (differential scanning calorimetry) study revealed no such incompatibility found between the pure drug and polymers but slight change in crystalinity were observed in XRD study (X-ray diffraction). SEM (scanning electron microscope) study revealed very rare intragranular pore and cavity.
\end{abstract}

Conclusion: From that, it can be marked as viscosity and selection of ethocel have great importance in delay drug release.

Keywords: Zidovudine hydrochloride, Ethocel, Innovator, Compression, Hardness

(C) 2018 The Authors. Published by Innovare Academic Sciences Pvt Ltd. This is an open access article under the CC BY license (http://creativecommons.org/licenses/by/4.0/) DOI: http://dx.doi.org/10.22159/ijpps.2018v10i3.24258

\section{INTRODUCTION}

Oral drug delivery is that the most generally used routes for administration of medicine, which are explored for general delivery via numerous pharmaceutical products as completely different dose kind [1]. In long-run medical care for the treatment of chronic disorders, typical formulations are needed to be administered oftentimes in multiple dose regimens, and thus have many undesirable effects. therefore so as to cut back the disadvantage related to multiple dosing, controlled or sustained unleash solid unit dosage forms as tablets were developed [2]. They typically produces higher patient compliance, maintain uniform drug therapeutic level, price effectiveness, broad regulative acceptance, cut back dose similarly as aspect effects and increase margin of error for top efficiency therapeutic agents [3].

HIV (human immune deficiency virus), the virus that causes AIDS, "acquired immunodeficiency syndrome," has become one in every of the world's most serious health and development challenges. The primary cases were reported in 1981 and these days. There are unit roughly thirty seven million individuals presently living with HIV and tens of countless individuals have died of AIDS-related causes since the start of the epidemic. Whereas new cases are reported altogether regions of the globe, roughly two-thirds area unit in geographic region, with forty third of latest cases in eastern and Southern continent [4]

Zidovudine comes in category of drugs known as nucleoside reverse transcriptase inhibitors-NRTIs. This drug together with other concurrent HIV medicine to help control spreading of retroviral infection [5]. It helps to decrease the amount of spreading HIV infection in body so that our immune system does better. This lowers chance of getting HIV complications and improves patient quality of life. This drug has more contribution towards prevention of HIV infection from infected mother to newborn. However serious side effects also marked in certain cases such as lactic acidosis, myopathy, weakness, immune reconstitution inflammatory syndrome, blood anemia, unusual breathing, dark color urine, neutropenia, muscle pain etc [6]. Such above mentioned cases always associated in chronic administration of dosage. In order to reduce such kind of severe and ill effect to patients controlled and fabricated dosage form are always being proved one step forward in proving safety and efficacy. Very few literature studies have been reported in use of ethyl cellulose and hydroxyl propyl methyl cellulose (HPMC) in matrices drug delivery. Generally the controlled dosage forms or matrix tablets are fabricated by selecting suitable hydrophilic and hydrophobic polymer [7, 8]. Hence novelty of the proposed work is to use various grades of ethocel in combined use of HPMC in a matrix tablet of anti retroviral drug.

Thus, an attempt has been made to formulate the extended-release matrix tablets of zidovudine $\mathrm{HCl}$ and affect of various grades of ethocel such as ethocel 4CPS, ethocel 7CPS and aqualon T10 Pharm EC on release of zidovudine were also observed and studied. During the study various findings were observed and those interpretated data could be used in large scale production.

\section{MATERIALS AND METHODS}

\section{Materials}

Zidovudine $\mathrm{HCl}$ was received as gift sample from Cipla LTd, Mumbai. Hydroxy-propyl methyl cellulose (HPMC K4M, HPMC K15M) and ethyl cellulose (ethocel 4CPS, ethocel 7CPS and aqualon T10 Pharm EC) were purchased from Loba Chemie, Mumbai, India. Dicalcium phosphate and polyvinyl pyrolidone (kollidon 30) were purchased from BASF Global (Germany). Colloidal silicon dioxide (aerosil-R 972) was received as gift sample from Ajanta ltd, India. All remain high analytical grades of chemicals, solvent and iso propyl alcohol (IPA) was purchased from Merck chemicals, India. 


\section{Method for preparation of tablets}

Zidovudine $\mathrm{HCl}$, HPMC K4M, HPMC K15M, dicalcium phosphate, ethocel 4CPS, ethocel 7CPS aqualon T10 Pharm EC and kollidon CLSF were passed through \#70 mesh and collected separately in polyethylene bag (table 1). Wet granulation technique was applied for the batch preparation of matrix tablets. All the materials were sifted to rapid mixing pilot scale granulator (SSPM System and Engineers, India) and mixed for 30 minute at optimized speed. Kollidon-30 was dissolved in the mixture of iso propyl alcohol (IPA) and Water (1:0.7) by the help of mechanical stirrer [9]. The above binder solution was added to dry mix and mixed for 20 minute to get wet mass. Then the resulted wet mass was dried at inlet temperature of $55^{\circ} \mathrm{C}$ to $65^{\circ} \mathrm{C}$ for 30 min and passed through multi mill (Bectochem, Ahmehdabad, India). The resulted dried granules were sifted through \#16 mesh and milled through Multi mill. The comminuted granules were lubricated with aerosil-R 972 for $10 \mathrm{~min}$. Finally, the lubricated granules were compressed to formulate tablets using tablet compression machine (Cadmach Machinery Pvt. Ltd, Puna, India) with $10 \mathrm{~mm}$ spherical shaped punches $[10,11]$.

Table 1: Composition of tablet formulation (mg)

\begin{tabular}{|c|c|c|c|c|c|c|c|c|c|c|}
\hline S. No. & Ingredients & F1 & F2 & F3 & F4 & F5 & F6 & F7 & F8 & F9 \\
\hline 1 & Zidovudine Hydrochloride & 250 & 250 & 250 & 250 & 250 & 250 & 250 & 250 & 250 \\
\hline 2 & Dicalcium phosphate & 150 & 150 & 150 & 150 & 150 & 150 & 150 & 150 & 150 \\
\hline 3 & Ethocel 4CPS & 10 & - & - & 5 & 5 & - & - & 5 & 10 \\
\hline 4 & Ethocel 7 CPS & - & 10 & - & - & 5 & 5 & - & - & - \\
\hline 5 & Aqualon T10 Pharm EC & - & - & 10 & 5 & - & 5 & 10 & 5 & - \\
\hline 6 & HPMC K4M & 25 & 25 & 25 & 25 & - & - & - & - & - \\
\hline 7 & HPMC K15M & - & - & - & - & 25 & 25 & 25 & 25 & 25 \\
\hline 8 & Kollidon 30 & 40 & 40 & 40 & 40 & 40 & 40 & 40 & 40 & 40 \\
\hline 9 & Isopropyl Alcohol & q.s. & q. s. & q. s. & q. s. & q. s. & q. s. & q. s. & q. s. & q. s. \\
\hline \multirow[t]{2}{*}{10} & Aerosil R 972 & 5 & 5 & 5 & 5 & 5 & 5 & 5 & 5 & 5 \\
\hline & Total Weight(mg) & 480 & 480 & 480 & 480 & 480 & 480 & 480 & 480 & 480 \\
\hline
\end{tabular}

\section{Micromeritic properties of prepared granules}

Prior to compression, granules were evaluated for their characteristic parameters [12]. Angle of repose was determined by funnel method. Bulk density (BD) and tapped density (TD) were determined by cylinder method, and carr's index (CI) was calculated using the following equation

$$
\mathrm{CI}=(\mathrm{TD}-\mathrm{BD}) / \mathrm{TD} \times 100 \ldots(1)
$$

Hausner's ratio (HR) was calculated by the following equation

$$
\text { HR=TD/BD....... (2) }
$$

\section{Physical characterization of matrix tablets}

The physiochemical characterizations of tablets were analyzed such as Hardness, friability, weight variation thickness and assay of compressed matrix tablet for each formulation were determined. Tablet hardness test was determined for 20 tablets using tablet hardness tester (Pfizer Tester) and the data reported is the mean of triplicate. Friability test was assessed to measure the strength of tablets as result to withstand mechanical shock, wears and tears. Preweighed randomly selected ten tablets were placed in a Roche friability tester and operated for $100 \mathrm{rpm}$. As per the limit of standardization the difference in weight should not more than $1 \%$ of their weigh. A weight variation test was performed according to USP30 NF25 on 20 tablets by taking samples from a batch after production of every 50 tablets and randomly from a total batch of 100 tablets using an electronic balance (Scientech SE-391, India). The thicknesses of tablets were measured by digital vernier callipers (Mitatoyo, Japan). The drug content in terms of assay of each batch was determined in triplicate. For each batch a number of 20 tablets were weighed and crushed to fine powder using mortar and pestle. An accurately equivalent weighed of $480 \mathrm{mg}$ of the powder was taken, crushed and suitably dissolved in methanol and analyzed by HPLC (high performance liquid chromatography) after making appropriate dilutions. The procedure was carried out on Shimadzu LC-2030 LT with flow rate of $0.5 \mathrm{ml} /$ minute at ambient temperature.

\section{In vitro dissolution studies}

In vitro release study was performed using United States pharmacopoeia (USP) dissolution testing apparatus II (paddle method). The dissolution test was performed using $900 \mathrm{ml}$ of Phosphate Buffer of $\mathrm{pH} 6.8$ at $37 \pm 0.5$ ${ }^{\circ} \mathrm{C}$ and $50 \mathrm{rpm}$ was fixed. At period of one hour interval $10 \mathrm{ml}$ sample solution were withdrawn and passed through membrane filter of 0.45 $\mu \mathrm{m}$. Samples were collected for time period of $12 \mathrm{~h}$. They were diluted with fresh phosphate buffer at suitable concentration and absorbances of those solutions were measured at $266 \mathrm{~nm}$ using a Shimadzu UV-2600 $\mathrm{UV} /$ Vis double beam spectrophotometer. The data represented in table in triplicate.

\section{Comparison of dissolution profile}

The similarity factor ( $f 2)$ given by scale up and post approval changes (SUPAC) guidelines [13] for a modified release dosage form was used as a basis to compare dissolution profile. The dissolution profiles are considered to be similar when $f 2$ is between $50-100$ and dissimilarity factor $(f 1)$ lies below 15 . The dissolution profiles of product was compared to Innovator (Zidine, Emcure-Innovator) using $f 2$ and $f 1$ which are calculated from the following formule,

$$
\begin{gathered}
f 2=50 \times \log \left\{\left[1+(1 / \mathrm{n}) \sum_{\mathrm{t}=1}{ }^{\mathrm{n}}\left|R_{\mathrm{t}}-T_{\mathrm{t}}\right|^{2}\right]-0.5 \times 100\right\} \ldots(3) \\
f 1=\left\{\left[\sum \mathrm{t}=1^{\mathrm{n}}\left|R_{\mathrm{t}}-T_{\mathrm{t}}\right|\right] /\left[\sum \sum_{\mathrm{t}=1^{\mathrm{n}}} R_{\mathrm{t}}\right]\right\} \times 100 \ldots \ldots(4)
\end{gathered}
$$

Where, $\mathrm{n}$ is the number of dissolution sample times and $\mathrm{R}_{\mathrm{t}}$ and $\mathrm{T}_{\mathrm{t}}$ are the individual or mean percent dissolved at each time point, $t$, for the innovator and test dissolution profiles, respectively.

\section{RESULTS AND DISCUSSION}

\section{Micromeritic properties of granules}

Micromeritic properties of precompressed granules were evaluated and cited in table 2 . The angle of repose found to be within limit of $33 \pm 3.83$ to $41 \pm 1.75$. Tapped density was between 0.502 to 0.593 and bulk density was found between 0.415 to 0.467 . The result cited in table indicated good flow as it varied from 33 to 41 . In addition to that, carr's index found to vary from 11.04 to 28.66 , which indicates good compressibility [14].

\section{Physical characterization of matrix tablets}

Physiochemical characterization of tablets were studied and displayed in table 3. The hardness of tables ranged from $4.9 \mathrm{~kg} / \mathrm{cm}^{2}$ to 5.9 $\mathrm{kg} / \mathrm{cm}^{2}$. During the study it observed that, formulations having ethocel grades of low viscosity have high crushing strength as compared to higher viscosity grades of ethocel as observed in aqualon T10 pharm EC. Formulation F1 exhibited higher crushing strength of $5.9 \mathrm{~kg} / \mathrm{cm}^{2}$ as it contained ethocel 4CPS and HPMC K4M. This is explained by the fact that ethocel of lower viscosity grades are more compressible and produced more harder tablet as observed during the study [15]. As per US pharmacopoeia the maximum percentage friability should not exceed $1 \%$. The prepared tablets lies within the acceptable and passed the friability test ranged from 0.17 to 0.45 . All the tablets showed excellent uniform thickness and no such variation was found. Average 
weight of each tablet ranged between $480.1 \pm 0.53 \mathrm{mg}$ to $482.1 \pm 1.07$ $\mathrm{mg}$. As per pharmacopoeia standard the weight of tablet more than $324 \mathrm{mg}$ should not beyond 5\% w/w [16-18]. The prepared tablet weight variation within the specified limit acceptance. Percentage of drug content in tablet found to be within the acceptable limit of $97.68 \%$ to $102.35 \%$.

Table 2: Micromeritic properties of prepared granules

\begin{tabular}{|c|c|c|c|c|c|c|}
\hline S. No. & $\begin{array}{l}\text { Formulation } \\
\text { code }\end{array}$ & $\begin{array}{l}\text { Bulk density } \\
(\mathrm{X} \pm \mathrm{SD})\end{array}$ & $\begin{array}{l}\text { Tapped density } \\
(\mathrm{X} \pm \text { SD) }\end{array}$ & $\begin{array}{l}\text { Hausner's } \\
\text { ratio }\end{array}$ & $\begin{array}{l}\text { Compressibility index (Carr's } \\
\text { index) }\end{array}$ & $\begin{array}{l}\text { Angle of repose } \\
(\mathrm{X} \pm \mathrm{SD})\end{array}$ \\
\hline 1 & F1 & $0.423 \pm 1.17$ & $0.502 \pm 1.36$ & 1.18 & 15.73 & $40 \pm 1.58$ \\
\hline 2 & $\mathrm{~F} 2$ & $0.428 \pm 2.11$ & $0.581 \pm 2.63$ & 1.35 & 26.33 & $41 \pm 1.75$ \\
\hline 3 & F3 & $0.467 \pm 2.1$ & $0.525 \pm 2.84$ & 1.12 & 11.04 & $37 \pm 2.84$ \\
\hline 4 & F4 & $0.423 \pm 1.51$ & $0.581 \pm 1.49$ & 1.37 & 27.19 & $35 \pm 2.83$ \\
\hline 5 & F5 & $0.415 \pm 2.19$ & $0.583 \pm 2.01$ & 1.4 & 28.81 & $35 \pm 1.06$ \\
\hline 6 & F6 & $0.425 \pm 1.61$ & $0.572 \pm 1.39$ & 1.34 & 25.69 & $33 \pm 3.83$ \\
\hline 7 & F7 & $0.431 \pm 3.01$ & $0.591 \pm 1.83$ & 1.37 & 27.07 & $38 \pm 2.94$ \\
\hline 8 & F8 & $0.423 \pm 2.11$ & $0.593 \pm 1.52$ & 1.4 & 28.66 & $37 \pm 2.05$ \\
\hline 9 & F9 & $0.425 \pm 1.42$ & $0.514 \pm 2.85$ & 1.2 & 17.31 & $39 \pm 2.52$ \\
\hline
\end{tabular}

Data are represented as mean \pm standard deviation $(\mathrm{SD}), \mathrm{n}=3$

Table 3: Physical characterization of the designed formulations

\begin{tabular}{|c|c|c|c|c|c|c|}
\hline S. No. & $\begin{array}{l}\text { Formulation } \\
\text { code }\end{array}$ & $\begin{array}{l}\text { Average weight (mg) } \\
(\mathrm{X} \pm \mathrm{Sd})\end{array}$ & $\begin{array}{l}\text { Thickness (mm) } \\
(\mathrm{X} \pm \text { Sd) }\end{array}$ & $\begin{array}{l}\text { Crushing strength } \\
\left(\mathrm{Kg} / \mathrm{cm}^{2}\right)\end{array}$ & $\begin{array}{l}\text { Drug content }(\%) \\
(\mathrm{X} \pm \mathrm{Sd})\end{array}$ & $\begin{array}{l}\text { Friability } \\
(\%)\end{array}$ \\
\hline 1 & F1 & $480.1 \pm 0.53$ & $4.27 \pm 1.01$ & $5.9 \pm 2.45$ & $98.38 \pm 2.19$ & $0.18 \%$ \\
\hline 2 & $\mathrm{~F} 2$ & $481.3 \pm 2.29$ & $4.17 \pm 1.12$ & $5.2 \pm 1.46$ & $102.35 \pm 3.17$ & $0.32 \%$ \\
\hline 3 & F3 & $482.0 \pm 1.27$ & $4.18 \pm 2.23$ & $5.6 \pm 2.55$ & $99.18 \pm 2.47$ & $0.26 \%$ \\
\hline 4 & $\mathrm{~F} 4$ & $481.6 \pm 0.29$ & $4.3 \pm 1.27$ & $5.4 \pm 3.06$ & $98.27 \pm 3.16$ & $0.28 \%$ \\
\hline 5 & F5 & $482.1 \pm 0.28$ & $4.26 \pm 0.98$ & $5.2 \pm 2.72$ & $99.25 \pm 1.39$ & $0.45 \%$ \\
\hline 6 & F6 & $480.5 \pm 1.15$ & $4.26 \pm 0.35$ & $5.0 \pm 3.25$ & $97.68 \pm 1.48$ & $0.17 \%$ \\
\hline 7 & F7 & $482.1 \pm 1.07$ & $4.27 \pm 0.87$ & $4.9 \pm 3.14$ & $100.01 \pm 4.52$ & $0.31 \%$ \\
\hline 8 & F8 & $480.6 \pm 0.57$ & $4.26 \pm 1.17$ & $5.1 \pm 2.45$ & $100.67 \pm 1.09$ & $0.27 \%$ \\
\hline 9 & F9 & $480.2 \pm 1.12$ & $4.26 \pm 1.12$ & $5.4 \pm 2.78$ & $99.09 \pm 3.08$ & $0.19 \%$ \\
\hline
\end{tabular}

Data are represented as mean \pm standard deviation (SD), $n=3$

\section{In vitro dissolution studies}

Different grades of ethocel like ethocel 4CPS, 7CPS and aqualon T10 were used to formulate zidovudine hydrochloride matrix tablet. The dissolution studies were performed in Phosphate Buffer of $\mathrm{pH} 6.8$ for maximum time period of $12 \mathrm{~h}$ as displayed in fig. 1 . In all the formulations the percentage of ethocel were fixed at $2 \%$ but the varied in grades of ethocel. The binder solution kollidon was fixed at $8 \%$ in all formulation. During the study the effect of two grades of HPMC such as HPMC K4M and HPMC K15M with ethocel were also studied. Result showed time needed for $100 \%$ of drug release from F8 was $12 \mathrm{~h}$, while F1 released $100 \%$ drug release within only $3 \mathrm{~h}$. It also observed that formulation F6 prepared with ethocel 7 CPS and aqualon T10 pharma EC release only $84.5 \%$ at $12 \mathrm{~h}$. This clearly indicated that, as ethocel 7 CPS replaces 4CPS; the drug release also extended for another $2 \mathrm{~h}$. From that point of view it could be concluded that as the more viscous grades of ethocel use; progressively the drug release also extended as observed in F7 and F9. Formulation F9 containing ethocel 4CPS at $2 \%$ released to $100 \%$, where as F7 contained T10 pharma EC released only $72 \%$ on $12 \mathrm{~h}$. During the study, it also observed formulations containing HPMC
K15M delayed drug release as compared to formulations prepared by HPMC K4M except F9, as the formulation contained only ethocel 4CPS. From the experiment it can also be remarked that, as the polymer viscosity increases the extent of release also increases and vice versa. In this study an remarkable finding was observed that, though the formulations containing lower viscosity grades of polymer and have higher crushing strength but the polymers having higher viscosity such as HPMC K15M prolonged the drug release to certain extend [19].

The data obtained from in vitro dissolution studies were fitted to zero-order, first-order, and higuchi release kinetics. All formulations were best fitted either to zero order or higuchi. The best fit with higher correlation coefficient $\left(r^{2}>0.997\right)$ was found with higuchi's equation for F8 and concluded the release of drug from tablet involves both dissolution and diffusion through polymers. To assertain the exact mechanism of drug release, the data were fitted by korsemeyer-peppas equation. The " $n$ " value lies between 0.41 to 0.51 . Hence it can be inferred that the release was based on quasi fickian and the release of drug had great impact by those hydrophobic polymer. On the basis of the above results, F8 was selected and preceded for further study.

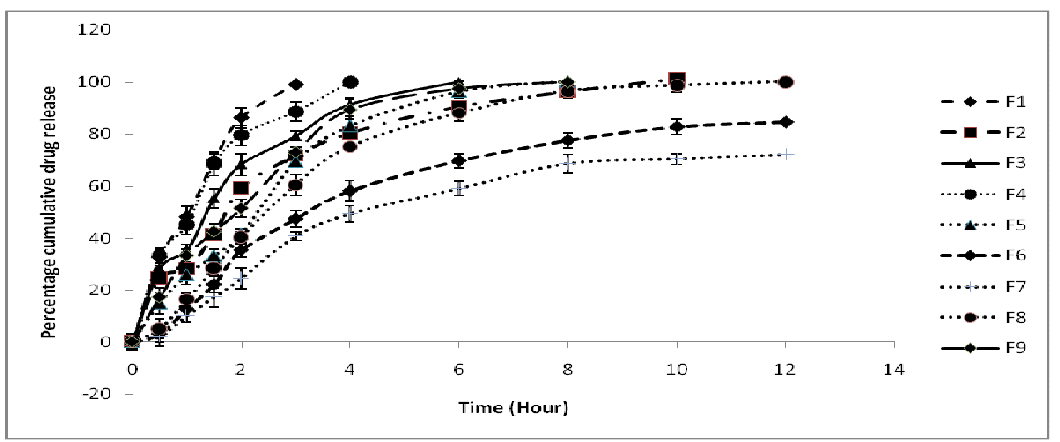

Fig. 1: In vitro dissolution study of all formulations, (Data are represented as mean \pm standard deviation (SD), $n=3$ ) 


\section{Comparison of dissolution profile}

The comparative results of the selected formulation batch F8 was compared with the theoretical dissolution profile (Zidine, EmcureInnovator) using the similarity factor $f 2$ test and dissimilarity factor $f 1$ test. The results of the similarity tests showed that formulation F8 had $f 2$ value $>50$ i.e. 64 , indicating the closest fit to the dissolution profile of innovator.

\section{Drug polymer interaction study}

\section{FT-IR study}

Pure zidovudine $\mathrm{HCl}$ mixed with ethocel 4CPS, ethocel 7CPS, aqualon T10 pharm EC dicalcium phosphate separately with IR grade $\mathrm{KBr}$ and pellets were prepared by applying a pressure of 10 tons in a hydraulic press. The pellets were scanned over a wavelength range of 450 to $4,500 \mathrm{~cm}^{-1}$ using an FTIR IRSpirit, Schimazu. There was no chemical interaction between zidovudine hydrochloride and the polymers used which is obtained by employing I. R. spectral studies (fig. 2 and fig. 3). The characteristic peak of carbonyl group at $1685.84 \mathrm{~cm}^{-1}$ and azide group at $2083.19 \mathrm{~cm}^{-1}$ indicated the stability of drug before and after formulation.

\section{DSC study}

Differential scanning calorimetry (DSC) has shown to be an important tool to quickly obtain information about possible interactions between the active and the excipients, according to the appearance, shift or disappearance of endothermic or exothermic peaks. DSC study was performed using Perkin Elmer DSC to determine the drug excepient compatibility study. During study a sharp endothermic peak for zidovudine hydrochloride was obtained at $131.55{ }^{\circ} \mathrm{C}$ corresponding to melting point (fig. 4). But in the formulation there was a slight change in peak temperature such as $106^{\circ} \mathrm{C}$ and $180^{\circ} \mathrm{C}$ (fig. 5), also a slight change in peak area and peak shape changed, which might be due to reduction of the purity percentage of component, appearance of adjacent polymer and interaction with solvent excipients [20, 21].

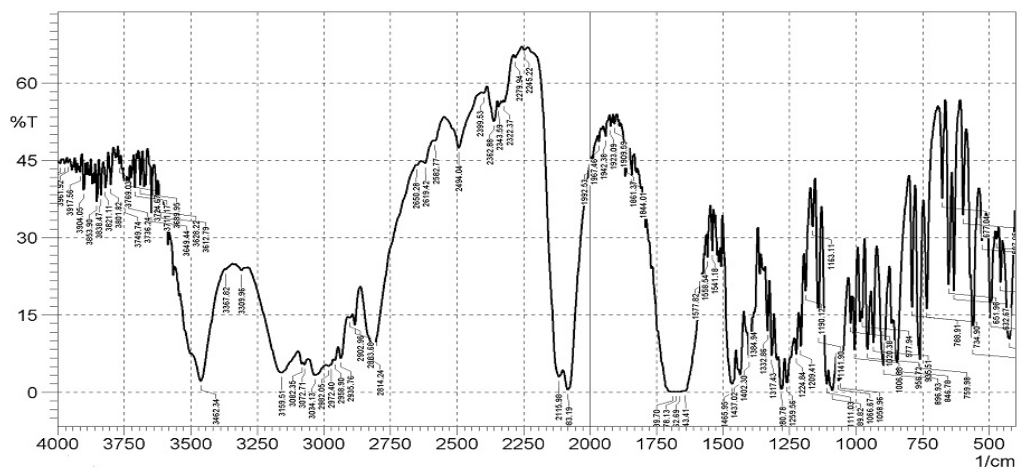

Fig. 2: FTIR spectrum of pure zidovudine hydrochloride

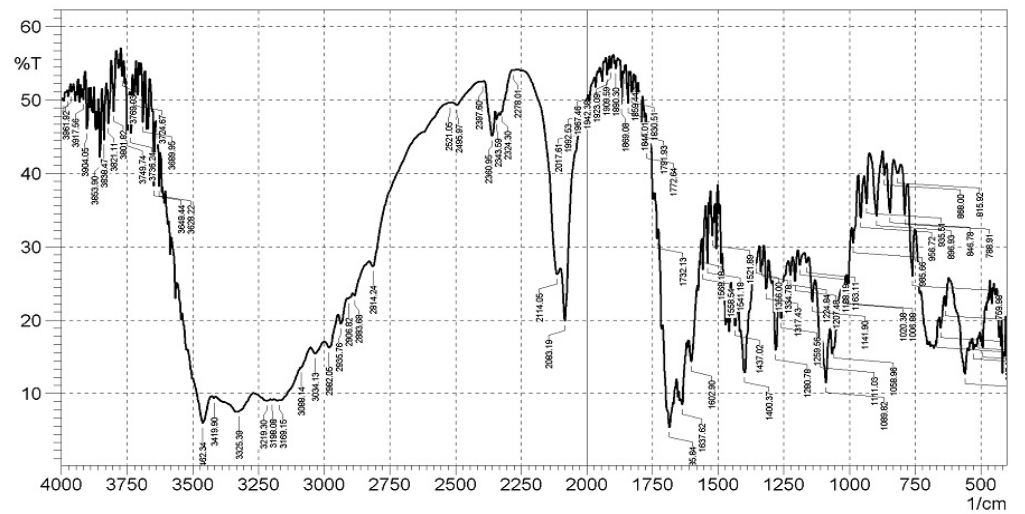

Fig. 3: FTIR Spectrum of formulation F8

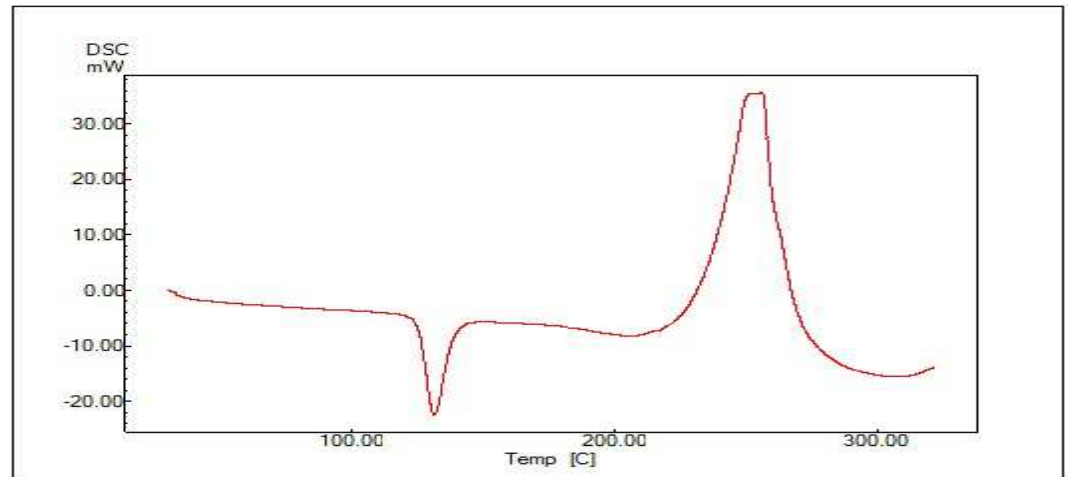

Fig. 4: DSC curve of pure zidovudine hydrochloride 


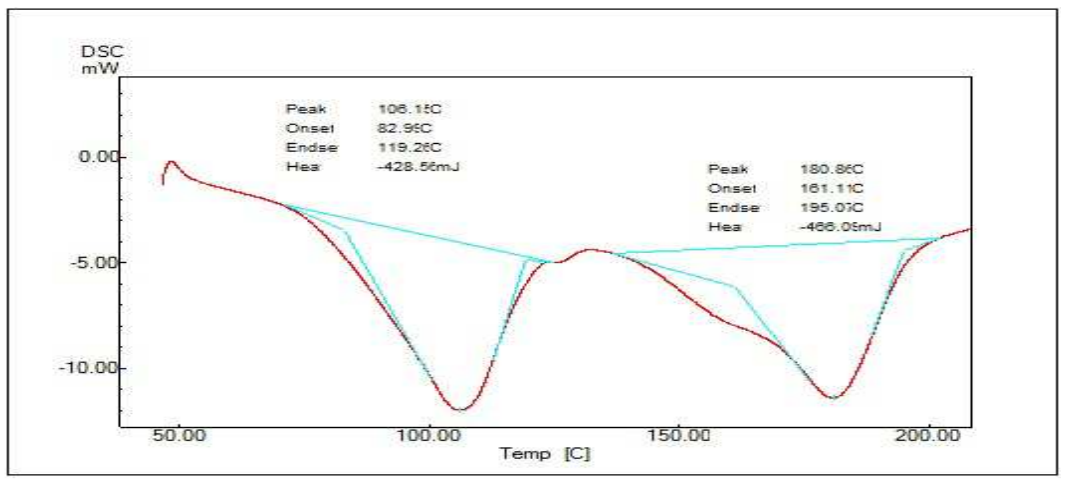

Fig. 5: DSC curve of formulation F8

\section{XRD study}

Change in crystalinity of drug can be determined by this technique. Pure drug and formulation components were analysed by the help of
XRD 7000, Shimadzu [22]. Pure zidovudine $\mathrm{HCl}$ showed the classical diffractogram of the crystalline substance. The XRD pattern of the formulation showed slight change in peak and pattern, indicated slight loss of crystalinity (fig. 6 and fig. 7).

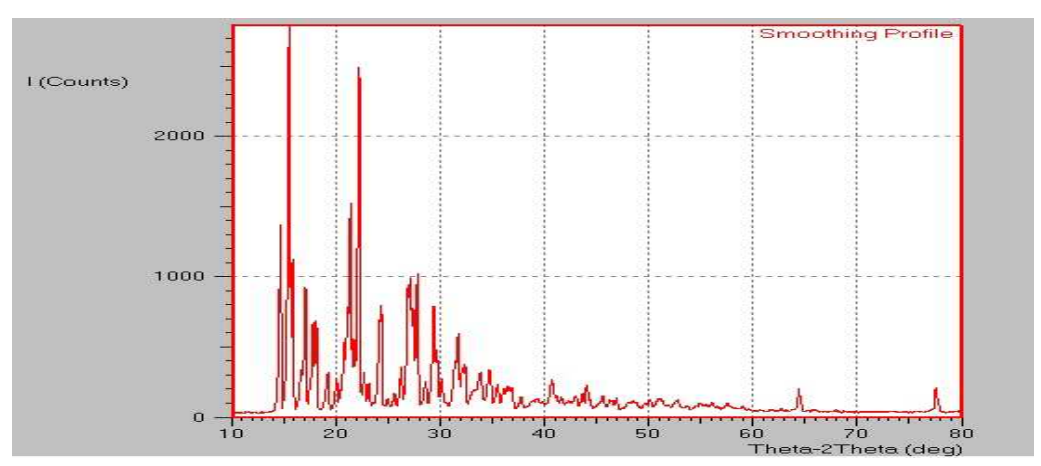

Fig. 6: XRD of pure zidovudine hydrochloride

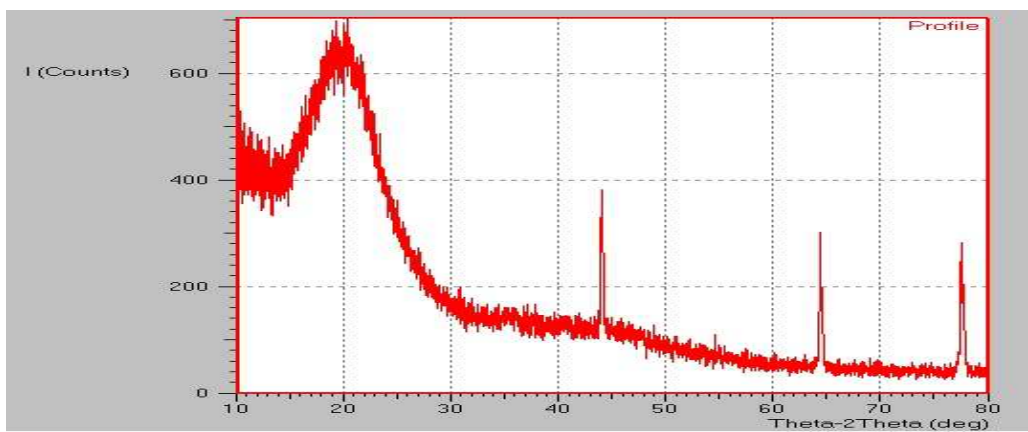

Fig. 7: XRD of formulation F8

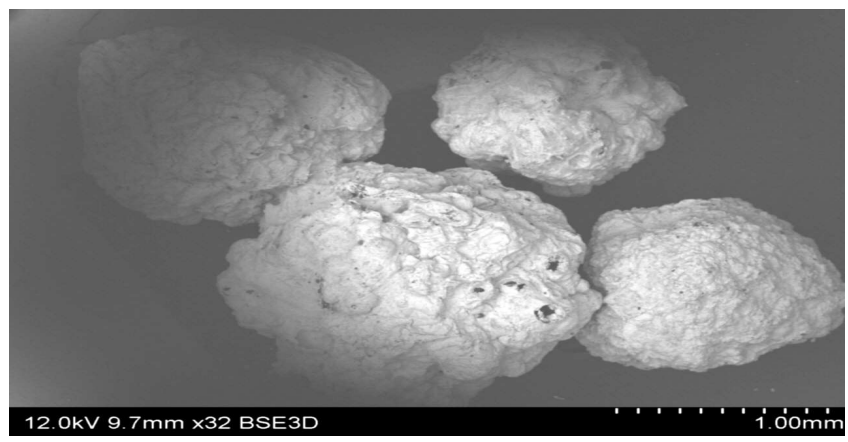

Fig. 8: SEM study of formulation F8 granules 


\section{SEM study}

In order to observed the surface morphology of prepared granule SEM Study was performed. It observed surface of granules were smooth and very rare intraparticular space (fig. 8). The studies revealed the surface of granules were covered well by ethocel; might be able to retard the free release of drug from tablet because of hydrophobic character [23] as compared to dummy granules prepared only by HPMC (not included in table 1 ).

\section{Stability study of best batch}

Long term, intermediate and accelerated stability testing study was carried out according to ICH guidelines considering $25 \pm 2{ }^{\circ} \mathrm{C} / 60 \pm 5 \%$ $\mathrm{RH}, 30 \pm 2{ }^{\circ} \mathrm{C} / 65 \pm 5 \% \mathrm{RH}$ and $40 \pm 2{ }^{\circ} \mathrm{C} / 75 \pm 5 \% \mathrm{RH}$ respectively. One hundred tablets of batch F8 were securely packed in aluminium blister and placed in humidity chamber [24]. There was no such major significance change in hardness and drug assay at a regular interval of 3 mo during the study of 24 mo as shown in table 4 .

Table 4: Stability study of best batch

\begin{tabular}{|c|c|c|c|c|c|c|}
\hline \multicolumn{7}{|c|}{ Long term stability study $\left(25 \pm 2{ }^{\circ} \mathrm{C}\right.$ and $\left.60 \pm 5 \% \mathrm{RH}\right)$} \\
\hline Month & 3 & 6 & 9 & 12 & 18 & 24 \\
\hline Drug assay $(\%)$ & $100.34 \pm 1.26$ & $100.15 \pm 2.17$ & $99.13 \pm 1.36$ & $99.09 \pm 2.65$ & $99.22 \pm 2.97$ & $98.17 \pm 1.49$ \\
\hline \multirow{2}{*}{$\begin{array}{l}\text { Crushing strength } \\
\left(\mathrm{Kg} / \mathrm{cm}^{2}\right)\end{array}$} & $5.8 \pm 4.15$ & $5.8 \pm 2.15$ & $5.8 \pm 1.58$ & $5.7 \pm 2.28$ & $5.7 \pm 2.71$ & $5.8 \pm 3.45$ \\
\hline & \multicolumn{6}{|c|}{ Intermediate stability $\left(30 \pm 2{ }^{\circ} \mathrm{C}\right.$ and $\left.65 \pm 5 \% \mathrm{RH}\right)$} \\
\hline Month & 3 & 6 & 9 & 12 & 18 & 24 \\
\hline Drug assay $(\%)$ & $100.14 \pm 2.26$ & $100.35 \pm 1.31$ & $99.47 \pm 0.96$ & $99.49 \pm 1.73$ & $99.67 \pm 3.15$ & $98.31 \pm 1.23$ \\
\hline \multirow{2}{*}{$\begin{array}{l}\text { Crushing strength } \\
\left(\mathrm{Kg} / \mathrm{cm}^{2}\right)\end{array}$} & $5.8 \pm 2.51$ & $5.8 \pm 2.06$ & $5.8 \pm 1.27$ & $5.8 \pm 1.08$ & $5.8 \pm 1.8$ & $5.7 \pm 2.05$ \\
\hline & \multicolumn{6}{|c|}{ Accelerated stability $\left(40 \pm 2{ }^{\circ} \mathrm{C}\right.$ and $\left.75 \pm 5 \% \mathrm{RH}\right)$} \\
\hline Month & 1 & 2 & 3 & 6 & - & - \\
\hline Drug assay (\%) & $100.07 \pm 3.15$ & $100.34 \pm 2.11$ & $99.98 \pm 1.02$ & $99.25 \pm 2.51$ & - & - \\
\hline $\begin{array}{l}\text { Crushing strength } \\
\left(\mathrm{Kg} / \mathrm{cm}^{2}\right)\end{array}$ & $5.8 \pm 1.69$ & $5.8 \pm 1.4$ & $5.8 \pm 1.09$ & $5.7 \pm 2.15$ & - & - \\
\hline
\end{tabular}

Data are represented as mean \pm standard deviation (SD), $n=3$

\section{CONCLUSION}

During this study extended release tablet of zidovudine $\mathrm{HCl}$ tablets were formulated. A total number of nine formulations were prepared by varying the amount of ethocel and HPMC. In this study the effect of various grades of ethocel with combination of HPMC studied. Result showed time took for F8 to release $100 \%$ drug was 12 hour. Moreover, it also observed that as viscosity of ethocel increased progressively extended the drug release. Formulation F8 compared with innovator and found to be providing satisfactory result. Furthermore, industrial grades of reproducible bathes and in vivo pharmacokinetic study have to carry out.

\section{AUTHORS CONTRIBUTIONS}

Author is a faculty in division of pharmaceutics and the work contributed on faculty development programme in the institution.

\section{CONFLICT OF INTERESTS}

\section{Declared none}

\section{REFERENCES}

1. Chien YW. Novel drug delivery systems. $2^{\text {nd }}$ ed. New York: Marcel Dekker; 1992.

2. Singh BN, Kim KH. Floating drug delivery system: an approach to oral controlled drug delivery via gastric retention. J Controlled Release 2000;63:235-59.

3. Brazel CS, Peppas NA. Temperature-and pH-sensitive hydrogels for controlled release of antithrombotic agents. Mater Res Soc Symp Proc 1994;331:211-6.

4. https://www.webmd.com/drugs/2/drug-4386/zidovudineoral/details. [Last accessed on 08 Sep 2017]

5. https://aidsinfo.nih.gov/drugs/4/zidovudine/0/patient. [Last accessed on 10 Sep 2017]

6. Santos JV, Pina ME, Marques MP, de Carvalho LA. New sustained release of Zidovudine Matrix tablets- cytotoxicity toward Caco-2 cells. Drug Dev Ind Pharm 2013;39:1154-66.

7. Ganesh S, Radhakrishnan M, Ravi M, Prasannakumar B, Kalyani J. In vitro evaluation of the effect of combination of hydrophilic and hydrophobic polymers on controlled release zidovudine matrix tablets. Indian J Pharm Sci 2008;70:461-5.

8. Kuksal A, Tiwary AK, Jain NK, Jain S. Formulation and in vitro, in vivo evaluation of extended-release matrix tablet of zidovudine: influence of combination of hydrophilic and hydrophobic matrix formers. AAPS PharmSciTech 2006;7:E1-9.

9. Tiwari SB, Murthy TK, Pai MR, Mehta PR, Chowdhary PB. Controlled release formulation of tramadol hydrochloride using hydrophilic and hydrophobic matrix system. AAPS PharmaSciTech 2003;4:110-6.

10. Harland R, Dubernet C, Benoit JP, Peppas NA. A model of dissolution-controlled, release from non-swellable polymeric microspheres. J Controlled Release 2003;6:282-91.

11. Streubel A, Siepmann J, Bodmeier R. Floating matrix tablets based on low density foam powder: Effect of formulation and process parameter on drug release. Eur J Pharm Sci 2003;18:37-45.

12. Aslani A, Fattahi F. Formulation, characterization and physicochemical evaluation of potassium citrate effervescent tablets. Adv Pharm Bull 2013;3:217-25.

13. Costa P, Manuel J, Labao S. Modeling and comparision dissolution profiles. Eur J Pharm Sci 2002;13:123-33.

14. Ritger PL, Peppas NA. A simple equation for description of solute release, II: Fickian and anomalous release from swellable devices. J Controlled Release 1987;5:37-42.

15. Goswami KO, Khurana GA, Marwaha RK, Gupta MI. Development and evaluation of extended release ethylcellulose based matrix tablet of diclofenac sodium. Int J Pharm Pharm Sci 2014;6:296-301.

16. Ramenskaya GV, Shlykov VS, Dekhanova OA. Comparative in vitro dissolution testing of trimetazidine prolonged-release tablets. Pharm Chem J 2009;43:677-9.

17. Elkhodairy KA, Hassan MA, Afifi SA. Formulation and optimization of orodispersible tablets of flutamide. Saudi Pharm J 2014;22:53-61.

18. Harekrishna Roy. Formulation of sustained release matrix tablets of metformin hydrochloride by polyacrylate polymer. Int J Pharma Res Health Sci 2015;3:900-6.

19. Md Mofizur R, Sumon R, Sreedam Chandra D, Mithilesh Kumar J, Taslima B, Md Qamrul A, et al. Evaluation of various grades of hydroxypropylmethylcellulose matrix systems as oral sustained release drug delivery systems. J Pharm Sci Res 2011;3:930-8.

20. Pawar HA, Dhavale R. Development and evaluation of gastroretentive floating tablets of an antidepressant drug by thermoplastic granulation technique. Beni-Suef University J Basic Appl Sci 2014;3:122-32. 
21. Song SH, Chae BR, Sohn SI, Yeom DW, Son HY, Kim JH, et al. Formulation of controlled-release pelubiprofen tablet using Kollidon® SR. Int J Pharm 2016;511:864-75.

22. Ravala JA, Patela JK, Naihong L, Patela MM. Ranitidine hydrochloride floating matrix tablets. Asian J Pharm Sci 2007;2:130-42.
23. Khan GM, Meidan VM. Drug release kinetics from tablet matrices based upon ethylcellulose ether-derivatives: a comparison between different formulations. Drug Dev Ind Pharm 2007;33:627-39.

24. Guideline IH. Stability testing of new drug substances and products. Q1A(R2), current step; 2003. p. 4. 